\title{
“One man's vodka is another man's firewater": international comparisons of drinking and drinking problems
}

\author{
RICHARD SMITH
}

Poland is a good place to hold a conference on alcohol. As I was driven from Warsaw airport to just such a conference on an autumnal Sunday afternoon we had to steer carefuly around a very drunk man staggering down the middle of the main road to Warsaw. A German delegate to the conference on the same afternoon saw the local fire brigade driving around the village in their fire engine, drunk to a man. (Later, a Polish psychiatrist explained that to be "as drunk as a fireman" was a traditional saying in Poland.) And on one evening of the conference three catastrophically drunk policemen "invaded" the "palace" where the conference was being held. Data presented at the conference showed that half of Poland's drinkers are drunk $20-40$ times a year, and $70 \%$ of respondents in a large national survey rated alcohol as the nation's most important social problem.

The main reason that the International Group for Comparative Alcohol Studies chose Poland was not, however, because of its outstanding alcohol problems but rather because of its strong tradition of alcohol research, a tradition shared by the Nordic countries and perhaps stimulated by the gross displays of public drunkenness. Thus about two dozen alcohol researchers from about a dozen countries got together to discuss drinking patterns and problems in their various countries to try to understand more about the motivations, mechanisms, and problems of drinking and about how alcohol related problems can be reduced.

The meeting was held in Zabarow, near Warsaw, in a white baroque palace that is still beautiful despite its uncut lawns and silted lake. The drunken antics that we saw may have been a September reaction to the Catholic Church naming August as national sobriety month. The church insists that Poles must stay sober to see "with truth" the appalling plight of their country, and the Polish Academy of Sciences has warned that: "In centuries to come encyclopaedias may describe the Poles conclusively as a nation that committed mass suicide, lost its natural instinct to live and drank itself to death."

Alcohol has intense political importance in Poland, and, as I wrote once before, at times of political conflict (which sadly seems to be most of the time in Poland) each side will try and seize the initiative and prove that it is more sober than the other. ${ }^{2}$ On this visit I went one cold night to see the grave of Father Jerzy Popieluszko, the priest who preached political sermons and was murdered by two policemen. About 300000 people attended his funeral (the population of Warsaw is only 1.5 million), and his grave has become a national shrine. Alcohol featured in his case: he had often preached against alcohol and had helped form the National Sobriety League, which now guards his grave and has since been picketing liquor stores. And the policemen who went to murder Father Popieluszko took two bottles of vodka with them. Their plan may have been to try and make it look as if the priest had died through drunken driving, which would have utterly discredited him.

British Medical Journal

RICHARD SMITH, MB, assistant editor
Alcohol was rationed in Poland around the time of the strikes in the Gdansk shipyards, the formation of Solidarity, and the subsequent imposition of martial law. Now, however, it is no longer rationed but is very much more expensive. In the late ' 70 s the average wage in Poland would have bought about 40 small bottles of vodka a month-now it will buy 20 . Official consumption figures show that alcohol consumption has thus come down from about 8 litres of pure alcohol a year for each person to about 6 litres. But Polish alcohol researchers estimate that about a quarter of all alcohol consumed is distilled illegally. People know how to distil in Poland because they did it during the war, and, as one Pole put it, "young men now go and ask their grandads how to distil." Distilling has also for the first time become popular among middle class and educated people.

The lesson here is that if a government tries to reduce the availability of alcohol too fast then people will make their own or find other sources. One thing that happens is that people begin to drink alcohol based perfumes and the like. In the main poisons unit in Warsaw about 50 cases of ethylene glycol poisoning are seen each year, and about a third of these patients die.

The same is likely to happen in Russia, where alcohol is now very hard to come by. Sadly, there were no Russians at the conference, but Polish psychiatrists who had recently visited Russia were talking of a new Russian song that goes: "When vodka is eight roubles a bottle we will go to Poland and when it is 20 roubles a bottle we will once again storm the Winter Palace."

\section{Reducing alcohol consumption: EEC inaction}

These Polish and Russian experiences illustrate the theme of the conference, which was a comparison of the three main ways of responding to alcohol problems: reducing overall consumption; changing drinking patterns so that they are less damaging; and treating and educating those with problems.

The main way to try and reduce overall consumption is to raise the price of alcohol, and the snag with this method is that all those who enjoy alcohol without suffering problems are also penalised. This is one reason why the political will to take such a step is completely lacking in most democratic countries.

An expert committee of the European Economic Committee recognised the importance of the evidence relating consumption and damage and in 1983 argued that an EEC "alcohol prevention policy" should prevent national per caput alcohol consumption from rising. To avoid charges of "neoprohibitionism" the community should also "promote moderate drinking practices and preserve the positive advantages of alcohol use.

Dr Herman Fahrenkrug, a medical sociologist from Freiburg, was given a grant by the EEC to find out how many EEC countries had such alcohol policies. After a year's work the answer in a nutshell was none. Greece even wrote to say that it effectively had no alcohol problem and that in 1982 it had had only 24 deaths from "alcoholism."

Just after Dr Fahrenkrug submitted his results the EEC once 
again emphasised the dangers of alcohol and called on members "to consider carefully the interests of production, distribution, and marketing of alcoholic beverage against the interests of public health and to pursue a balanced policy." Dr Fahrenkrug detects a gap between the reality and the rhetoric.

\section{Changing drinking patterns: the search for "lucky drinkers"}

Changing drinking patterns, the second approach to alcohol problems, is politically much more popular-not least because most people think that they can carry on drinking as before and that it will be somebody else's pattern that will have to change. The main snags with this approach, however, are that changing drinking patterns is very hard, the results are difficult to predict, and, although some types of harm associated with alcohol may be reduced, others may not. Furthermore, what is a safe pattern, what is "sensible drinking?"

Members of temperance movements, which are strong in Scandinavian countries and in Poland, object passionately to the idea of "sensible drinking" or even to "safe limits." The Polish National Antialcoholic Committee in Cracow, for instance, objected to the publication-in Polish-of the BMJ's $A B C$ of Alcohol: "... the booklet contains pseudomedical advice for family doctors . . . totally inconsistent with the basic principles of alcohology, with the truth about alcohol-the narcotic. The truths and principles...tell us that safe and harmless doses of alcohol do not exist and that so called "social drinking" [belongs to the] "nursery school" of alcoholism."

This contretemps between the Institute of Psychiatry and Neurology in Warsaw, which published the $B M \mathcal{F}$ book, and the committee in Cracow was mentioned in the introduction to a paper by two Polish sociologists-Jacek Moskalewicz and Grazyna Swiatkiewicz-on "lucky drinkers." From a national survey done in 1984 they identified about a fifth (629) of respondents who reported experiencing only positive effects from their drinking in the previous year. These were the "lucky drinkers," and the positive experiences they reported included "improvement of mood" (75\%), "easy manners in conversation" (60\%), "help in curing a cold" (21\%), and "achievement of positive results in business" $(16 \%)$.

The researchers then tried to work out how these "lucky drinkers" were different from the "unlucky" ones. Could it be, they wondered, that this group possessed the secret of safe drinking, the philosophers' stone of alcohologists? The main difference between the two groups turned out to be simply that the lucky drinkers drank less-an annual average of 13 litres of pure alcohol compared with 45 litres by the others. They also became intoxicated on fewer occasions, although more than half had been intoxicated on their last drinking occasion. Generally, too, the lucky drinkers were slightly less likely to drink unflavoured vodka (the main drink in Poland) and slightly more likely to drink at home with relations, but the differences were not striking - and socially and demographically they were not appreciably different from the unlucky drinkers. One difference was, however, that $58 \%$ of the lucky drinkers were women as opposed to only $36 \%$ of the unlucky ones.

The researchers' overall conclusion was that they had not found the philosopher's stone, and commentators suggested that one of the problems of the paper was that one year was perhaps too short a time to look for negative effects-someone who was "lucky" last year might be "unlucky" next, and many people who are "lucky" now may be "unlucky" in the future once the chronic effects of alcohol have had time to bite. Furthermore, "lucky" and perhaps myopic drinkers may be surrounded by people who are suffering consequences from the drinking of the "lucky" drinker. Nevertheless, this pursuit of the secret of lucky drinking will continue.

\section{Treatment: how to capture the market?}

The third response to alcohol problems is to concentrate on treating or educating those with alcohol related problems while leaving the rest to enjoy their alcohol. One snag with this approach is that many drinkers, if not most drinkers, might experience problems at one time or another during their drinking lives. But other snags with the treatment response are, firstly, that many of those with problems never come forward for treatment and, secondly, that both treatment and education are of doubtful efficacy.

One reaction to the failure of people to come for treatment is to "catch" them and treat them compulsorily, and such policies have been used, the conference heard, in Finland, Poland, and Hungary -without conspicuous success. As Dr Jacek Morawski of the Institute of Psychiatry and Neurology in Warsaw told the meeting, treatment for alcohol problems was abolished in Poland immediately after the war on the grounds that such problems would soon disappear because "they were the relics of the capitalist past in the consciousness of the people." By the ' 50 s compulsory inpatient and outpatient treatment was established, and alcoholics could be isolated in institutions for up to two years. In 1982 this too was abolished and replaced with "judicial obligation of submission to treatment," one of the main effects of which is to shift "repressive and executory functions from health services." Self help organisations are also now permitted.

Dr Zsuzsanna Elekes from Budapest compared the social characteristics of 80 people treated compulsorily in Hungary, 80 treated voluntarily, and 80 treated with short detoxification treatment because of "scandalous public inebriateness." Voluntary patients tend to be younger and from a better social background than those treated compulsorily, and the result of those compulsorily treated is as a rule poor. Those detoxified for public drunkenness are the "most deprived, most helpless stratum of the society," and the detoxification (for which they have to pay) does little or nothing for them.

Compulsory treatment thus does not have a good record, and $\mathrm{Dr}$ Doug Cameron, a psychiatrist from the community alcohol team in Leicester, has tried something "completely different." The team doesn't accept the disease concept of alcoholism and lets the clients tell them what they want. The treatment is entirely in the community (but for occasional short term inpatient detoxification of people with little or no social support), and "treatments" offered include a huge range of interventions, most of them not directly related to alcohol. No very formal evaluation of this project has been done, but Dr Cameron presented evidence to show that six months after starting treatment a cohort of 135 patients had changed their drinking patterns appreciably - and for the "better." Perhaps more impressive were his data showing that his team is now treating about 1000 people a year, whereas when the programme began in 1978 only about 100 people were being treated. The Leicester team is also willing to take anybody back, but the rereferral rate is only $11 \%$. The team thus seems to have made considerable progress with getting to patients with alcohol problems, but there must be more scientific doubt about how successfully they are treating them.

\section{Conclusion}

A few minutes in Poland and you see some of the problems that alcohol causes. A few conversations and you begin to understand the immense political and social importance of the liquid. Doctors are forced to become interested in alcohol because of the alcohol related problems they face every day. The interest of social scientists, who predominated at the conference, is more-to paraphrase one of the slogans of medicine-that "if you understand the use and abuse of alcohol in a society you understand the society." This is one thing that I learnt at this conference, but I also understood better that any programme to respond to alcohol problems must follow all three of the possible responses: reducing overall consumption; encouraging "healthier" drinking patterns; and finding better, which probably means ever less formal, ways of treating alcohol problems.

\section{References}

1 Anonymous. Abstinence month. Listener 1986 Aug 14:17

2 Smith R. Polish lessons on alcohol policy. Br Med J 1982;284:98-101. 